\title{
Paroxysmal Atrial Fibrillation Coincident With Cardiac Decompensation is a Predictor of Poor Prognosis in Chronic Heart Failure
}

\author{
Toshimi Koitabashi, MD; Takayuki Inomata, MD; Shinichi Niwano, MD; \\ Mototsugu Nishii, MD; Ichiro Takeuchi, MD; Hironari Nakano, MD; \\ Hisahito Shinagawa, MD; Hitoshi Takehana, MD; Tohru Izumi, MD
}

\begin{abstract}
Background The prognostic significance of atrial fibrillation (AF) in chronic heart failure (CHF) remains poorly understood.

Methods and Results Death and rehospitalizaion for CHF exacerbation for 427 consecutive patients hospitalized from 1996 to 2002 were retrospectively analyzed in relation to cardiac rhythm: sinus rhythm (SR; n=239) or AF $(n=188)$. The AF group was classified according to an Intervention $(n=57)$ or Non-Intervention $(n=131)$ group for defibrillating AF. During the follow-up of $34 \pm 23$ months, there was no significant difference of mortality or morbidity between the SR and AF groups, or between the Intervention and Non-Intervention groups, respectively. However, the Non-Intervention group consisted of 28 patients with paroxysmal AF (PAF), which spontaneously converted to SR during hospitalization, and 103 with chronic AF (CAF). The rehospitalization for CHF exacerbation was significantly higher in PAF than that in CAF and SR ( $\mathrm{p}=0.00005$ and 0.002 , respectively). Multivariate Cox analysis demonstrated that, $\mathrm{PAF}$, but not CAF, was a predictor of readmission (relative risk $2.30, \mathrm{p}=0.004,95 \%$ confidence interval 1.30 to 4.05 ).

Conclusions The present data implied that PAF coincident with cardiac decompensation could be a new predictor of prognosis for CHF. The management strategies of AF in CHF should be discussed according to the phenotype of AF. (Circ J 2005; 69: 823-830)
\end{abstract}

Key Words: Heart failure; Paroxysmal atrial fibrillation; Prognosis

$A$ trial fibrillation (AF) is the most common type of arrhythmia in clinical practice and it is responsible for substantial morbidity and mortality 1,2 Based on its pathophysiological and epidemiological background, it had long been believed that rhythm control for AF, including defibrillation and maintenance of sinus rhythm (SR), was the preferable type of management. However, the Atrial Fibrillation Follow-up Investigation of Rhythm Management (AFFIRM) study recently showed no significant difference in the overall prognosis of patients with $\mathrm{AF}$ between rate and rhythm control managements?

Chronic heart failure (CHF) is an increasingly frequent cardiovascular disorder worldwide and it has been reported that $\mathrm{AF}$ is markedly more prevalent among patients with CHF than in the general population, 4,5 The prognostic significance of AF in CHF, however, remains poorly understood. Although many clinical studies have supported the hypothesis that the presence or development of $\mathrm{AF}$ in patients suffering from CHF, or left ventricular (LV) dysfunction? is associated with a higher mortality, there have been some reports with neutral conclusions, ${ }^{8,9}$ or even finding a beneficial impact of $\mathrm{AF}$ on the prognosis of

(Received December 8, 2004; revised manuscript received April 11, 2005; accepted April 27, 2005)

Department of Internal Medicine and Cardiology, Kitasato University School of Medicine, Sagamihara, Japan

Mailing address: Toshimi Koitabashi, MD, Department of Internal Medicine \& Cardiology, Kitasato University School of Medicine, 115-1 Kitasato, Sagamihara 228-8555, Japan. E-mail: toshimi@pk9. so-net.ne.jp
$\mathrm{CHF} !^{10}$ Furthermore, the strategy for the treatment of AF in patients with CHF is still controversial.

The purpose of the present study was to investigate the clinical impact of AF on the prognostic value for CHF, especially according to the clinical forms of $\mathrm{AF}$ classified by its onset and persistence.

\section{Methods}

Patients

The study population consisted of consecutive patients with exacerbated heart failure diagnosed with congestive heart failure, according to the Framingham criteria, admitted to Kitasato University Hospital from January 1996 to September 2002. Patients with acute myocardial infarction or permanent pacemaker implantation and patients who dropped out from the outpatient management in this hospital were excluded. The patients were divided into 2 groups according to basic cardiac rhythm during hospitalization: 239 patients were in sinus rhythm with no documentation of AF during hospitalization (SR Group) and 188 patients were diagnosed with AF during hospitalization (AF Group). Patients in the AF Group were further classified into 2 groups according to the management for $\mathrm{AF}$ retrospectively: 57 patients who had electrical or pharmacological defibrillation, or had been administered antiarrhythmic agents for the prevention of $\mathrm{AF}$ recurrence were included in the Intervention Group, and 131 who did not have aggressive therapy for AF stated as above, with the exception of ventricular rate control, were included in the Non-Intervention 
Table 1 Baseline Characteristics of Patients in the SR and AF Groups

\begin{tabular}{|c|c|c|}
\hline & $\begin{array}{l}\text { SR group } \\
(n=239)\end{array}$ & $\begin{array}{c}\text { AF group } \\
(n=188)\end{array}$ \\
\hline Age, mean, years $(S D)$ & $65.2(14.5)$ & $66.9(12.5)$ \\
\hline Female, no. (\%) & $99(41.4)$ & $54(28.7) * *$ \\
\hline \multicolumn{3}{|l|}{ On admission } \\
\hline NYHA, II:III: IV & $10: 63: 166$ & $4: 59: 125$ \\
\hline$L A D, m m(S D)$ & $41.5(8.7)$ & $46.9(11.2)$ \\
\hline$L V D d, m m(S D)$ & $58.8(10.6)$ & $55.8(9.4)^{* *}$ \\
\hline$L V E F, \%(S D)$ & $34.7(14.9)$ & $39.3(16.2)^{* *}$ \\
\hline$B N P, p g / m l(S D)$ & $810(635)$ & $603(520) * *$ \\
\hline \multicolumn{3}{|l|}{ On discharge } \\
\hline$L A D, m m(S D)$ & $38.9(6.7)$ & $43.9(10.2)$ \\
\hline$L V D d, m m(S D)$ & $58.4(10.1)$ & $54.4(9.9) * *$ \\
\hline$L V E F, \%(S D)$ & $38.6(15.1)$ & $45.8(14.6)^{* *}$ \\
\hline$B N P, p g / m l(S D)$ & $219(274)$ & $204(246)$ \\
\hline \multicolumn{3}{|c|}{ Underlying cardiovascular disease no. (\%) } \\
\hline$I H D$ & $124(51.9)$ & $65(34.6) * *$ \\
\hline$D C M$ & $65(27.2)$ & $37(19.7)$ \\
\hline$H C M$ & $4(1.7)$ & $4(2.1)$ \\
\hline$V H D$ & $37(15.5)$ & $75(39.9) * *$ \\
\hline$H H D$ & $40(16.7)$ & $30(20.0)$ \\
\hline Other & $11(4.6)$ & $7(3.7)$ \\
\hline \multicolumn{3}{|c|}{ Underlying complications no. (\%) } \\
\hline$D M$ & $88(36.8)$ & $47(25.0) * *$ \\
\hline$H T$ & $151(63.2)$ & $98(52.1) *$ \\
\hline$C V D$ & $26(10.9)$ & $26(13.8)$ \\
\hline \multicolumn{3}{|l|}{ Medication use no. (\%) } \\
\hline$\beta$-blockers & $81(33.9)$ & $66(35.1)$ \\
\hline$A C E$ inhibitors $/ A R B$ & $199(83.3)$ & $152(80.9)$ \\
\hline Digoxin & $77(32.2)$ & $120(63.8) * *$ \\
\hline Diuretics & $211(88.3)$ & $162(86.2)$ \\
\hline Aspirin & $142(59.4)$ & $97(51.6)$ \\
\hline Warfarin & $69(28.9)$ & $94(50.0) * *$ \\
\hline \multicolumn{3}{|l|}{ Death no. (\%) } \\
\hline Total death & $45(18.8)$ & $31(16.5)$ \\
\hline $\mathrm{CHF}$ & 19 & 11 \\
\hline$C P A$ & 7 & 6 \\
\hline$V F / V T$ & 2 & 1 \\
\hline$A M I$ & 1 & 0 \\
\hline Stroke & 2 & 11 \\
\hline Other & 13 & 2 \\
\hline \multicolumn{3}{|l|}{ Readmission for } \\
\hline CHF exacerbation & $89(37.2)$ & $60(31.9)$ \\
\hline \multicolumn{3}{|l|}{ Other reasons } \\
\hline$C P A$ & $7(2.9)$ & $4(2.1)$ \\
\hline$V F / V T$ & $7(2.9)$ & $8(4.3)$ \\
\hline$A M I$ & $3(1.3)$ & $0(0.0)$ \\
\hline Cerebral infarction & $8(3.3)$ & $11(5.9)$ \\
\hline Cerebral hemorrhage & $3(1.3)$ & $0(0.0)$ \\
\hline Bleeding & $4(1.7)$ & $7(3.7)$ \\
\hline Embolic event & $1(0.4)$ & $2(1.1)$ \\
\hline
\end{tabular}

NYHA, New York Heart Association; LAD, left atrial dimension; LVDd, left ventricular end-diastolic dimension; $L V E F$, left ventricular ejection fraction; BNP, B-type natriuretic peptide; IHD, ischemic heart disease; $D C M$, dilated cardiomyopathy; HCM, hypertrophic cardiomyopathy; $V H D$, valvular heart disease; $H H D$, hypertensive heart disease; DM, diabetes mellitus; HT, hypertension; CVD, cerebrovascular disease; $A C E$, angiotensin-converting enzyme; $A R B$, angiotensin-receptor blocker; $C P A$, cardiopulmonary arrest; $V F$, ventricular fibrillation; VT, ventricular tachycardia; AMI, acute myocardiac infarction.

$* * * p<0.05$ and $p<0.01$ vs SR group, respectively.

Group. The in-hospital management strategy against AF for individual patients was decided based on the consensual opinion of 2 experienced cardiologists. Total death and rehospitalization for $\mathrm{CHF}$ exacerbation were retrospectively analyzed from hospital discharge until September 2002 (follow-up period of 1-72 months; $34.3 \pm 23.3$ months).

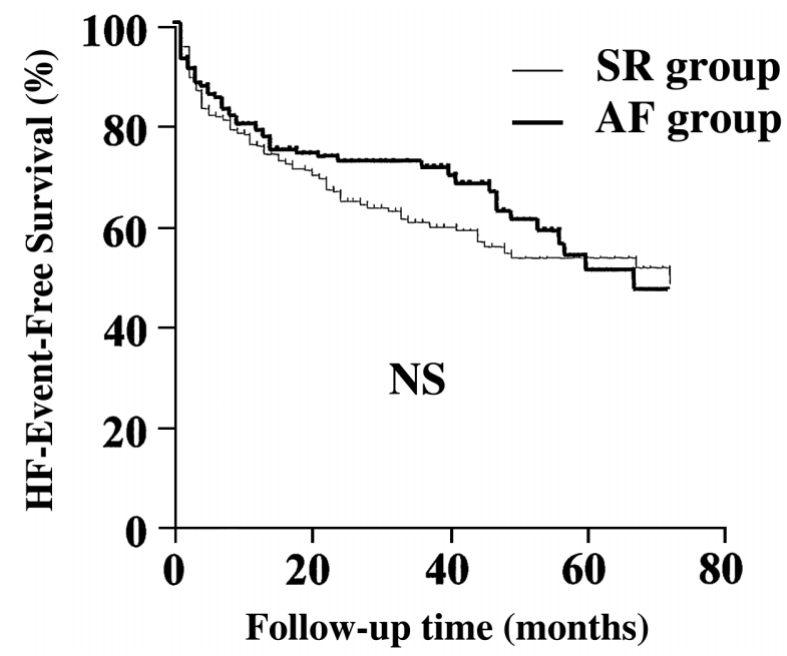

Fig 1. Kaplan-Meier survival curves estimated for the SR and AF group. There was no significant difference in morbidity between patients with CHF in SR or in AF. HF-Event-Free Survival indicates the event-free rate for CHF exacerbation with readmission.

\section{Clinical Measurement of $\mathrm{CHF}$}

Clinical parameters at discharge were analyzed as the patient baseline characteristics for CHF. Venous blood samples for neurohumoral factors were taken from an antecubital vein after $15 \mathrm{~min}$ of rest. Plasma B-type natriuretic peptide (BNP) was determined by sensitive noncompetitive immunoradiometric assays (Shionoria $\mathrm{BNP}^{\circledR}$ ). Findings on ultrasonic cardiography were recorded by a SONOS 500 (Hewlett Packard, USA). The dimension of each chamber was measured in the left parasternum view using M mode, and the ejection fraction (EF) was calculated using a modified Simpson method.

\section{Statistical Analysis}

Continuous data are expressed as mean \pm SD. Patient characteristics were compared using the chi-squared test and Mann-Whitney U-test. The event-free rates among the groups were calculated using the Kaplan-Meier method, and the difference among the groups was detected using the log-rank test. Statistical significance was defined as a p-value of $<0.05$ (one-sided) for all analyses. The Cox proportional hazards model was applied to evaluate differences in the occurrence of death or rehospitalization for $\mathrm{CHF}$ exacerbation among the groups after taking into account the effect of several potential confounders using SPSS software (11.0.1J for Windows, SPSS Inc, Chicago, USA).

\section{Results}

Prognostic Value of $A F$ in $C H F$

As shown in Table 1, the clinical background was similar between the SR Group and AF Group, although there were significant differences in left atrial dimension (LAD), LVEF, basal heart diseases and the administered frequency of digitalis and warfarin. Approximately one-third of each group was readmitted for CHF exacerbation during the 72month-follow-up period. There was no significant difference in mortality $(\mathrm{p}=0.41$, data not shown) or morbidity between these 2 groups ( $\mathrm{p}=0.64$, Fig 1$)$. 
Table 2 Baseline Characteristics of Patients in the I and NI Groups

\begin{tabular}{|c|c|c|}
\hline & $\begin{array}{l}\text { I group } \\
(n=57)\end{array}$ & $\begin{array}{l}\text { NI group } \\
(n=131)\end{array}$ \\
\hline Age, mean, years $(S D)$ & $61.8(12.9)$ & $69.3(11.9) * *$ \\
\hline Female, no. $(\%)$ & $10(17.5)$ & $44(33.5) *$ \\
\hline \multicolumn{3}{|l|}{ On admission } \\
\hline NYHA, II:III: IV & 3:10:44 & 1:49:81* \\
\hline$L A D, m m(S D)$ & $44.2(8.8)$ & $48.0(11.9) * *$ \\
\hline$L V D d, m m(S D)$ & $55.4(7.9)$ & $56.0(10.0)$ \\
\hline$L V E F, \%(S D)$ & $39.0(17.8)$ & $39.4(15.7)$ \\
\hline$B N P, p g / m l(S D)$ & $533(435)$ & $642(561)$ \\
\hline \multicolumn{3}{|l|}{ On discharge } \\
\hline$L A D, m m(S D)$ & $41.6(9.0)$ & $44.9(10.6) *$ \\
\hline$L V D d, m m(S D)$ & $52.9(9.8)$ & $55.0(10.0)$ \\
\hline LVEF, \% (SD) & $46.0(14.4)$ & $45.7(14.8)$ \\
\hline$B N P, p g / m l(S D)$ & $146(175)$ & $239(275) * *$ \\
\hline \multicolumn{3}{|c|}{ Underlying cardiovascular disease no. (\%) } \\
\hline$I H D$ & $19(33.3)$ & $46(35.1)$ \\
\hline$D C M$ & $19(33.3)$ & $18(13.7) *$ \\
\hline$H C M$ & $3(5.3)$ & $1(0.8)$ \\
\hline$V H D$ & $15(26.3)$ & $60(45.8) *$ \\
\hline$H H D$ & $6(10.5)$ & 24 (18.3) \\
\hline Other & $1(1.8)$ & $6(4.6)$ \\
\hline \multicolumn{3}{|c|}{ Underlying complications no. (\%) } \\
\hline$D M$ & $10(17.8)$ & $37(28.2)$ \\
\hline$H T$ & $19(33.3)$ & $79(60.3) * *$ \\
\hline$C V D$ & $5(8.8)$ & $21(16.0)$ \\
\hline \multicolumn{3}{|l|}{ Medication use no. (\%) } \\
\hline$\beta$-blockers & $27(47.4)$ & $39(29.8) *$ \\
\hline$A C E$ inhibitors/ARB & $47(82.5)$ & $105(80.2)$ \\
\hline Digoxin & $32(56.1)$ & $88(67.2)$ \\
\hline Diuretics & $46(80.1)$ & $116(88.5)$ \\
\hline Aspirin & $29(50.9)$ & $68(51.9)$ \\
\hline Warfarin & $28(49.1)$ & $66(50.4)$ \\
\hline \multicolumn{3}{|l|}{ Death no. (\%) } \\
\hline Total death & $7(12.3)$ & $24(18.0)$ \\
\hline $\mathrm{CHF}$ & 3 & 8 \\
\hline$C P A$ & 1 & 5 \\
\hline$V F / V T$ & 1 & 0 \\
\hline$A M I$ & 0 & 0 \\
\hline Stroke & 0 & 11 \\
\hline Other & 2 & 0 \\
\hline \multicolumn{3}{|l|}{ Readmission for } \\
\hline CHF exacerbation & $13(22.8)$ & $47(35.3)$ \\
\hline \multicolumn{3}{|l|}{ Other reasons } \\
\hline$C P A$ & $2(3.5)$ & $2(1.5)$ \\
\hline$V F / V T$ & $3(5.3)$ & $5(3.8)$ \\
\hline AMI & $0(0.0)$ & $0(0.0)$ \\
\hline Cerebral infarction & $5(8.8)$ & $6(4.5)$ \\
\hline Cerebral hemorrhage & $0(0.0)$ & $0(0.0)$ \\
\hline Bleeding & $1(1.8)$ & $6(4.5)$ \\
\hline Embolic event & $1(1.8)$ & $1(0.8)$ \\
\hline
\end{tabular}

I group, Aggressive Intervention group; NI group, Non-Intervention group, other abbreviations as Table 1.

$*, * * p<0.05$ and $p<0.01$ vs I group, respectively.

\section{Prognostic Value of Treatment Strategy for AF in $\mathrm{CHF}$}

As shown in Table 2, clinical parameters were very similar between the Intervention Group and Non-Intervention Group except age, LAD, plasma BNP and basal heart diseases. There was no significant difference of mortality $(\mathrm{p}=0.37$, data not shown) or morbidity $(\mathrm{p}=0.20$, Fig 2$)$ between these 2 groups.

Paroxysmal AF $(P A F)$ as a Prognostic Indicator for $\mathrm{CHF}$

The AF Group could further be classified according to the clinical forms of AF by its onset and persistence as shown in Fig 3. The Non-Intervention Group consisted of 28 patients with PAF, which spontaneously converted to SR during hospitalization and another 103 with chronic AF

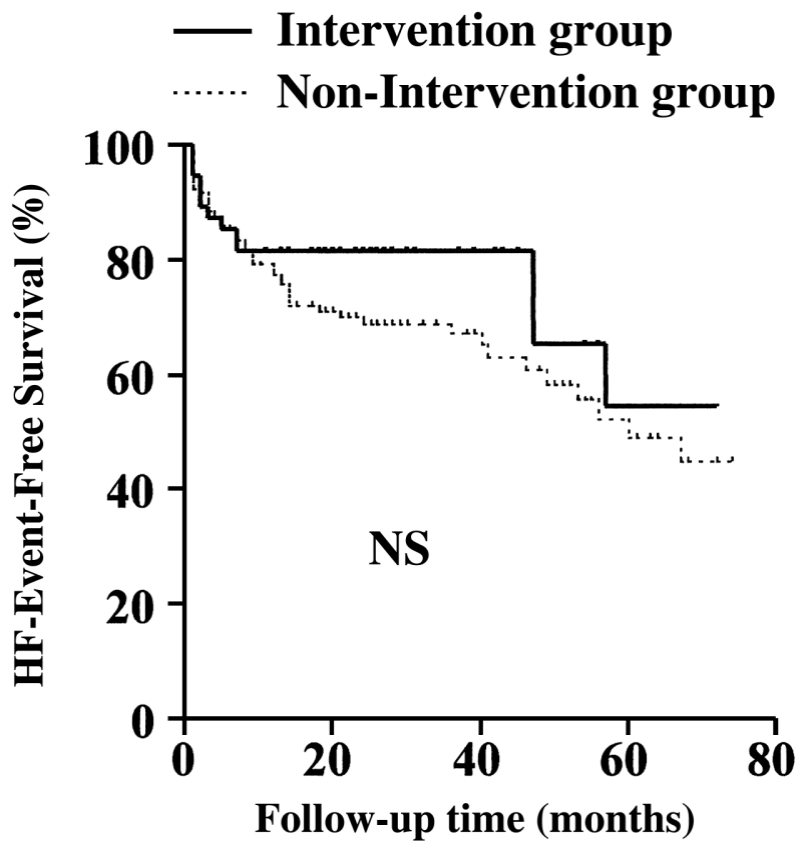

Fig 2. Kaplan-Meier survival curves estimated for the Intervention and Non-Intervention groups of the AF group. There was no significant difference of morbidity between patients with or without attempting defibrillation of $\mathrm{AF}$.

(CAF). When we compared the prognosis of these 2 groups, the rehospitalization rate due to $\mathrm{CHF}$ exacerbation was significantly higher in PAF than that in CAF $(\mathrm{p}=0.00005$, Fig 4) at the statistical power of $80 \%$, although there was no significant difference in total death. It was remarkable that $25.0 \%$ of the patients had died and a further $64.3 \%$ suffered CHF exacerbation leading to readmission during the follow-up period in the PAF group (Table 3). When comparing the prognosis with that of the SR Group, there was no significant difference between SR and CAF while the rehospitalization rate was significantly higher in PAF than that in SR ( $p=0.002$; Fig 4). As shown in Table 3, there was no significant difference in the clinical parameters with the exception of LAD, complicated frequency of myocardial ischemia and diabetes mellitus between PAF and CAF, and with the exception age between PAF and SR. In multivariate Cox analysis, the existence of PAF, but not CAF, was a significant predictor of readmission for CHF exacerbation (relative risk 2.30, $\mathrm{p}=0.004,95 \%$ confidence interval 1.30 to 4.05 ) (Table 4$)$.

Further analysis of PAF during the follow-up period after discharge demonstrated that 25 out of 28 cases $(89 \%)$ maintained SR while they had a stable CHF status as outpatients, while PAF was again documented at hospital readmission with $\mathrm{CHF}$ exacerbation in 12 out of 17 cases $(70 \%)$.

\section{Discussion}

\section{Pathophysiological and Prognostic Contribution of AF} to $\mathrm{CHF}$

It has been emphasized that AF may compromise LV systolic function and worsen $\mathrm{CHF}$ through poor rate control, irregularity of the ventricular response, and loss of atrial transport,${ }^{11}$ as well as tachycardia-induced cardiomyopathy ${ }^{12}$ Conversely, some reports insisted that $\mathrm{CHF}$ itself could 


\section{On admission}

\section{Exacerbated heart failure and $\mathrm{AF}$}

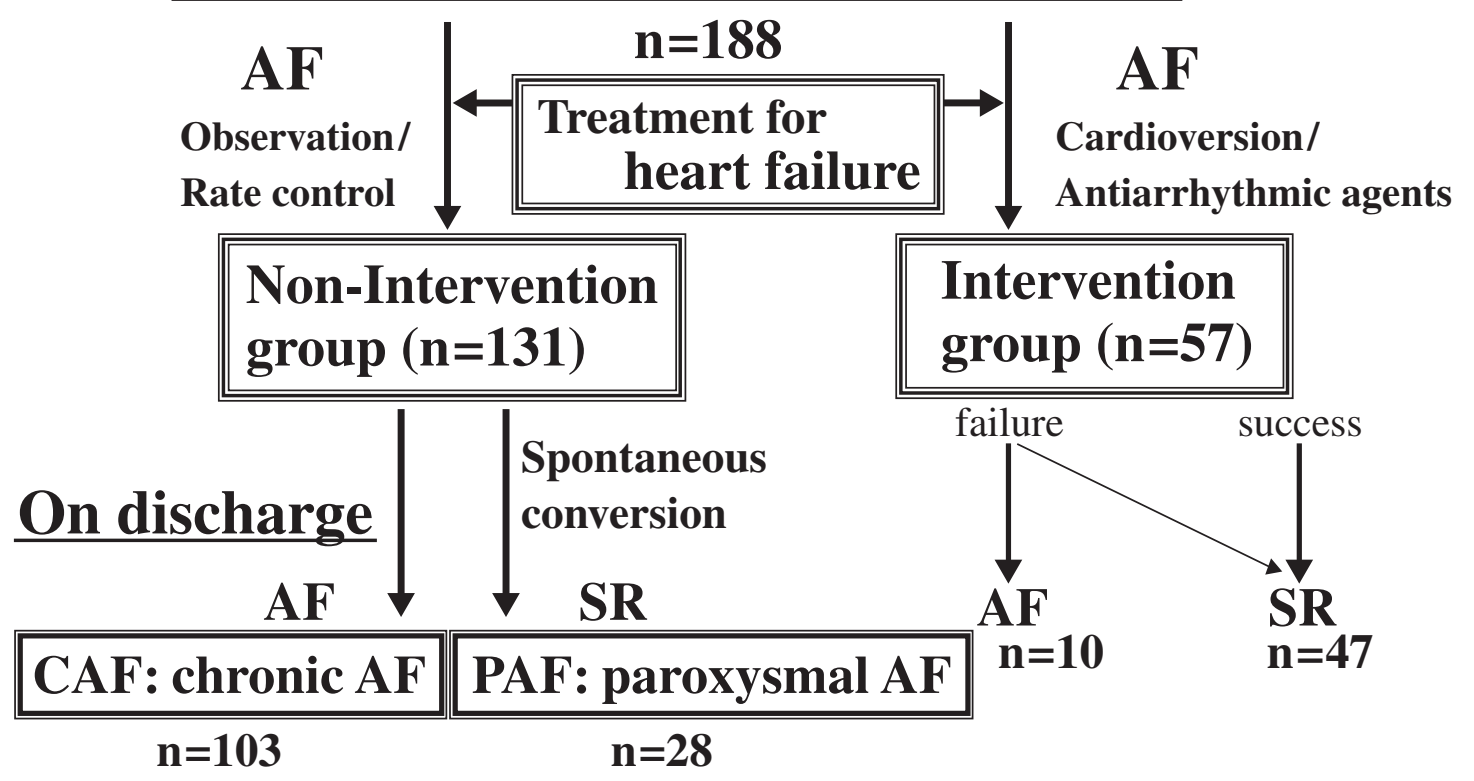

Fig 3. The Non-Intervention group included patients with paroxysmal AF (PAF), which spontaneously converted to SR during hospitalization with the improvement of $\mathrm{CHF}$ and chronic $\mathrm{AF}$ (CAF).

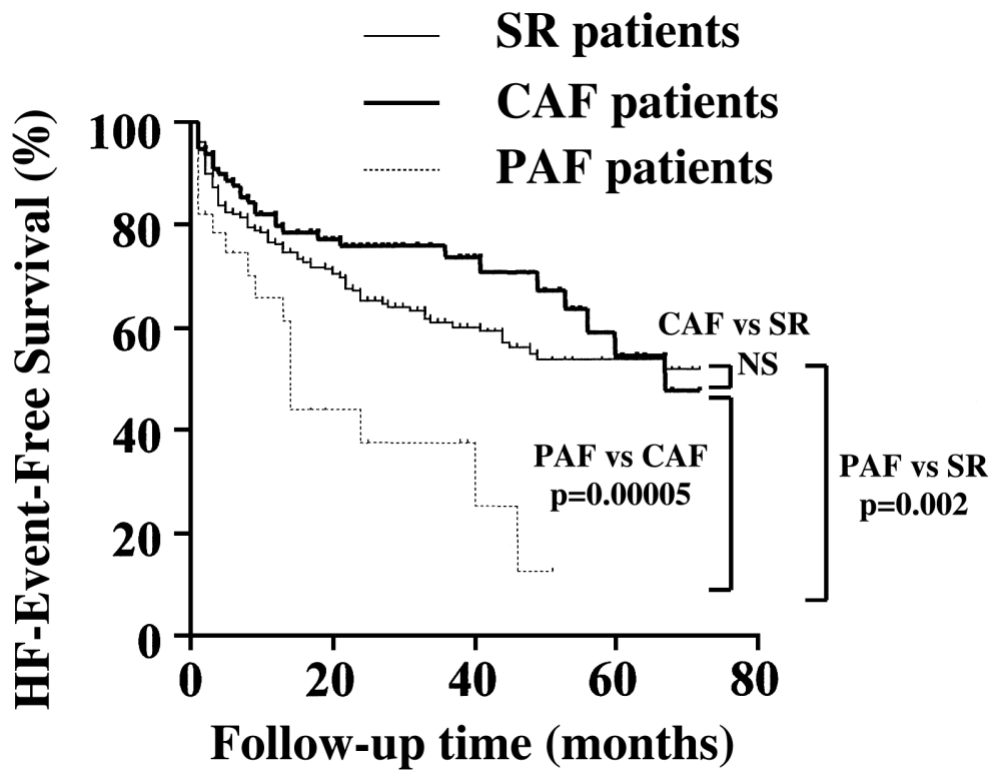

Fig 4. Kaplan-Meier survival curves estimated for patients with SR, CAF and PAF. There was no significant difference of morbidity between patients with SR or CAF. However, rehospitalization for exacerbated CHF was markedly higher in patients with PAF than those with SR or CAF. contribute to the prevalence of complicated AF through atrial remodeling or activated neurohumoral factors, including sympathetic and renin-angiotensin-aldosterone systems $!^{13,14}$

Although it is recognized that individuals with $\mathrm{AF}$ are at an increased risk of death in the general population, ${ }^{2}$ the impact of $\mathrm{AF}$ on $\mathrm{CHF}$ mortality has remained controversial despite being examined extensively. V-HeFT trials found that baseline AF was not related to overall mortality or sudden death? SOLVD trials, however, reported that AF was associated with increased mortality? Studies based on CHF patients at transplant centers have reached conflicting conclusions 15,16 Some studies have even reported that AF has a beneficial impact on the prognosis in CHF $!^{10}$ Disparities between prior studies may be derived from several biases that reflect the focus on prevalence rather than the incidences of the disease, $7,9,16$ varying duration of AF and $\mathrm{CHF}^{9}, 15$ and the characteristics of different referral populations?,10,15 It has been suggested that AF is only independently associated with increased mortality rates in patients with relatively preserved LV function, while the relationship is more complicated and dependent on other variables in individuals with advanced disease 8,15 Wang et al reported that antecedent AF was not a significant predictor of mor- 
Table 3 Baseline Characteristics of Patients With SR, PAF and CAF

\begin{tabular}{|c|c|c|c|}
\hline & $\begin{array}{c}S R \\
(n=239)\end{array}$ & $\begin{array}{c}P A F \\
(n=28)\end{array}$ & $\begin{array}{c}C A F \\
(n=103)\end{array}$ \\
\hline Age, mean, years $(S D)$ & $65.2(14.5)$ & $70.6(13.6) * *$ & $68.7(11.1)^{* *}$ \\
\hline Female, no. (\%) & $99(41.4)$ & $6(21.4)$ & $38(27.3)$ \\
\hline Time of previous admission (SD) & $1.4(0.9)$ & $1.4(0.7)$ & $1.6(1.1)$ \\
\hline \multicolumn{4}{|l|}{ On admission } \\
\hline NYHA, II:III:IV & 10:63:166 & $0: 08: 20$ & $1: 41: 61^{*}$ \\
\hline$L A D, m m(S D)$ & $41.5(8.7)$ & $41.6(8.0)$ & $49.9(12.0) * *, s$ \\
\hline$L V D d, m m(S D)$ & $58.8(10.6)$ & $55.4(10.5)$ & $56.2(9.9) *$ \\
\hline$L V E F, \%(S D)$ & $34.7(14.9)$ & $37.1(13.8) * *$ & $40.0(16.1)^{* *}$ \\
\hline$B N P, p g / m l(S D)$ & $810(635)$ & $903(723)$ & $570(491)^{* *, \dagger}$ \\
\hline \multicolumn{4}{|l|}{ On discharge } \\
\hline$L A D, m m(S D)$ & $38.9(6.7)$ & $37.4(6.3)$ & $46.9(10.6) * *, 8$ \\
\hline$L V D d, m m(S D)$ & $58.4(10.1)$ & $54.5(11.1)$ & $55.2(9.7) *$ \\
\hline$L V E F, \%(S D)$ & $38.6(15.1)$ & $43.4(13.1)^{*}$ & $46.3(15.2) * *$ \\
\hline$B N P, p g / m l(S D)$ & $219(274)$ & $291(301)$ & $223(268)$ \\
\hline \multicolumn{4}{|c|}{ Underlying cardiovascular disease no. (\%) } \\
\hline$I H D$ & $124(51.9)$ & $18(64.3)$ & $28(27.2) * *, 8$ \\
\hline$D C M$ & $65(27.2)$ & $3(10.7)$ & $15(14.6) *$ \\
\hline$H C M$ & $4(1.7)$ & $0(0.0)$ & $1(1.0)$ \\
\hline$V H D$ & $37(15.5)$ & $4(14.3)$ & $56(54.4) * *, \S$ \\
\hline$H H D$ & $40(16.7)$ & $7(25.0)$ & $17(16.5)$ \\
\hline Other & $11(4.6)$ & $0(0.0)$ & $6(5.8)$ \\
\hline \multicolumn{4}{|l|}{ Underlying complications no. (\%) } \\
\hline$D M$ & $88(36.8)$ & $15(53.6)$ & $22(21.4) * *, \S$ \\
\hline$H T$ & $151(63.2)$ & $18(64.3)$ & $61(59.2)$ \\
\hline$C V D$ & $26(10.9)$ & $2(7.1)$ & $19(18.4)$ \\
\hline \multicolumn{4}{|l|}{ Medication use no. (\%) } \\
\hline$\beta$-blockers & $81(33.9)$ & $12(42.9)$ & $27(26.2)$ \\
\hline$A C E$ inhibitors $/ A R B$ & $199(83.3)$ & $22(78.6)$ & $83(80.6)$ \\
\hline Digoxin & $77(32.2)$ & $11(39.3)$ & $77(74.8) * *, \$$ \\
\hline Diuretics & $211(88.3)$ & $22(78.6)$ & $94(91.3)$ \\
\hline Aspirin & $142(59.4)$ & $19(67.9)$ & $49(47.6) *$ \\
\hline Warfarin & $69(28.9)$ & $12(42.9)$ & $54(52.4) * *$ \\
\hline \multicolumn{4}{|l|}{ Death no. (\%) } \\
\hline Total death & $45(18.8)$ & $17(16.2)$ & $7(25.0)$ \\
\hline $\mathrm{CHF}$ & 19 & 5 & 3 \\
\hline$C P A$ & 7 & 4 & 1 \\
\hline$V F / V T$ & 2 & 0 & 0 \\
\hline$A M I$ & 1 & 0 & 0 \\
\hline Stroke & 2 & 8 & 3 \\
\hline Other & 13 & 0 & 0 \\
\hline \multicolumn{4}{|l|}{ Readmission for } \\
\hline CHF exacerbation & $89(37.2)$ & $29(27.6)$ & $18(64.3)$ \\
\hline \multicolumn{4}{|l|}{ Other reasons } \\
\hline$C P A$ & $7(2.9)$ & $1(1.0)$ & $1(3.6)$ \\
\hline$V F / V T$ & $7(2.9)$ & $4(3.8)$ & $1(3.6)$ \\
\hline AMI & $3(1.3)$ & $0(0.0)$ & $0(0.0)$ \\
\hline Cerebral infarction & $8(3.3)$ & $5(4.8)$ & $1(3.6)$ \\
\hline Cerebral hemorrhage & $3(1.3)$ & $0(0.0)$ & $0(0.0)$ \\
\hline Bleeding & $4(1.7)$ & $3(2.9)$ & $3(10.7)$ \\
\hline Embolic event & $1(0.4)$ & $1(1.0)$ & $0(0.0)$ \\
\hline
\end{tabular}

SR, sinus rhythm; PAF, paroxysmal atrial fibrillation; $C A F$, chronic atrial fibrillation; other abbreviations as Table 1 . $*_{* * *}^{*}<0.05$ and $p<0.01$ vs SR patients, ${ }^{\dagger}$ and ${ }^{\xi} p<0.05$ and $p<0.01$ vs PAF patients, respectively.

tality in subjects with CHF because the high mortality associated with $\mathrm{CHF}$ in the community might overwhelm the modest influence of preexisting AF, particularly after adjustment for other cardiovascular conditions $!^{17} \mathrm{We}$ found in the present study population that the persistent or temporal existence of $\mathrm{AF}$ during the hospitalized course of $\mathrm{CHF}$ exacerbation was associated with morbidity. These fundamental data could lead us to focus on how to categorize and to deal with $\mathrm{AF}$ coincident with exacerbated $\mathrm{CHF}$ in further studies.

\section{PAF as a New Predictor of Prognosis for $\mathrm{CHF}$}

In the present study, we found a unique impact of PAF on the prognosis of $\mathrm{CHF}$ as a new predictor. The PAF group categorized in our study had the peculiarity that $\mathrm{AF}$ was documented with CHF exacerbation and restored to SR with stabilizing CHF status. Although one report showed conflicting data that patients with PAF have a better prognosis than those with CAF in the general population ${ }^{18}$ its clinical value to patients with CHF has scarcely been investigated so far. To consider the causative mechanism of PAF on a worse prognostic value for CHF, we should focus on 2 paradigms: the patients' cardiac status predisposed them to the occurrence of AF; and acute hemodynamic alteration mainly derived from the cessation of regular sinus rhythm.

The predisposition of CHF to AF roughly consists of 2 pathomechanisms: irreversible and reversible processes. 
Table 4 Variables in the Cox Proportional Hazards Model

\begin{tabular}{|c|c|c|c|c|c|c|}
\hline \multirow[t]{2}{*}{ Variables } & \multicolumn{3}{|c|}{$\begin{array}{l}\text { Readmission for CHF } \\
\text { exacerbation end-point }\end{array}$} & \multicolumn{3}{|c|}{ Death end-point } \\
\hline & $R R$ & $95 \% C I$ & $p$ value & $R R$ & $95 \% C I$ & $p$ value \\
\hline$C A F$ & 0.637 & $0.361-1.125$ & 0.121 & 0.952 & $0.436-2.078$ & 0.901 \\
\hline$P A F$ & 2.297 & $1.302-4.053$ & 0.004 & 1.765 & $0.715-4.360$ & 0.218 \\
\hline Male & 1.527 & $1.021-2.283$ & 0.039 & 1.346 & $0.767-2.362$ & 0.300 \\
\hline Age & 1.034 & $1.015-1.053$ & 0.000 & 1.018 & $0.992-1.044$ & 0.175 \\
\hline \multicolumn{7}{|l|}{ On admission } \\
\hline NYHA & 0.870 & $0.625-1.211$ & 0.410 & 1.236 & $0.753-2.029$ & 0.401 \\
\hline$L A D$ & 1.016 & $0.993-1.040$ & 0.184 & 1.019 & $0.986-1.053$ & 0.268 \\
\hline LVDd & 0.994 & $0.969-1.019$ & 0.625 & 1.000 & $0.964-1.039$ & 0.980 \\
\hline$E F$ & 1.004 & $0.989-1.020$ & 0.585 & 1.000 & $0.977-1.024$ & 0.985 \\
\hline$B N P$ & 1.000 & $0.999-1.000$ & 0.155 & 1.000 & $1.000-1.001$ & 0.598 \\
\hline \multicolumn{7}{|l|}{ On discharge } \\
\hline NYHA & 1.630 & $1.111-2.392$ & 0.012 & 1.603 & $0.905-2.840$ & 0.106 \\
\hline$L A D$ & 1.009 & $0.975-1.044$ & 0.611 & 1.037 & $0.991-1.086$ & 0.116 \\
\hline LVDd & 1.018 & $0.989-1.048$ & 0.216 & 0.992 & $0.951-1.035$ & 0.712 \\
\hline$E F$ & 1.005 & $0.986-1.024$ & 0.631 & 0.980 & $0.952-1.009$ & 0.170 \\
\hline$B N P$ & 1.002 & $1.001-1.003$ & 0.000 & 1.001 & $1.000-1.002$ & 0.127 \\
\hline \multicolumn{7}{|c|}{ Underlying cardiovascular disease } \\
\hline$I H D$ & 1.234 & $0.720-2.115$ & 0.444 & 0.660 & $0.301-1.448$ & 0.300 \\
\hline$D C M$ & 1.191 & $0.589-2.407$ & 0.627 & 0.670 & $0.248-1.811$ & 0.430 \\
\hline$V H D$ & 0.866 & $0.509-1.475$ & 0.597 & 0.407 & $0.177-0.939$ & 0.035 \\
\hline$H H D$ & 0.889 & $0.499-1.583$ & 0.689 & 1.380 & $0.635-2.999$ & 0.416 \\
\hline \multicolumn{7}{|l|}{ Underlying complications } \\
\hline$D M$ & 1.206 & $0.795-1.829$ & 0.379 & 0.982 & $0.516-1.869$ & 0.956 \\
\hline$H T$ & 1.018 & $0.680-1.525$ & 0.930 & 1.370 & $0.745-2.520$ & 0.311 \\
\hline$C V D$ & 1.296 & $0.764-2.198$ & 0.336 & 1.664 & $0.787-3.518$ & 0.182 \\
\hline \multicolumn{7}{|l|}{ Medication use } \\
\hline$\beta$-blockers & 0.815 & $0.524-1.270$ & 0.366 & 0.415 & $0.200-0.861$ & 0.018 \\
\hline$A C E$ inhibitors $/ A R B$ & 0.789 & $0.509-1.222$ & 0.288 & 1.119 & $0.587-2.130$ & 0.733 \\
\hline Digoxin & 1.048 & $0.696-1.577$ & 0.823 & 1.063 & $0.577-1.957$ & 0.845 \\
\hline Diuretics & 1.833 & $0.910-3.692$ & 0.090 & 0.531 & $0.245-1.150$ & 0.108 \\
\hline Warfarin & 0.494 & $0.308-0.794$ & 0.004 & 0.505 & $0.255-1.001$ & 0.050 \\
\hline Aspirin & 0.889 & $0.591-1.338$ & 0.573 & 0.294 & $0.165-0.525$ & 0.000 \\
\hline
\end{tabular}

RR, Risk ratio; 95\% CI, 95\% confidence interval; other abbreviations as Tables 1 and 3.

The former originates from organic changes, including atrial fibrosis, regional conduction abnormalities and electrophysiological changes such as a shortened atrial refractory period chronically caused by CHF 19,20 The latter occurs via acutely increased atrial filling pressure and atrial dilatation? The significant impact of PAF should be derived from the reversible hemodynamic or cardiac background considering the pathomechanism stated above. Diastolic ventricular dysfunction causes a secondary increase in filling pressure and mediates atrial remodeling, and is associated with a 5.26-fold increase of the risk of AF development compared with normal diastolic function.1 Complications of abnormal parameters for diastolic dysfunction, such as ischemic heart disease, hypertensive heart disease and diabetes mellitus, in the PAF group, although not significant, might contribute to the prevalence of PAF. Because it has been demonstrated that diastolic dysfunction could induce a poorer prognosis among CHF patients, similar to systolic function,2 the diastolic property needs to be elucidated to better understand the causative mechanism. Left atrial dilatation is the only parameter that differentiates CAF from PAF. Because chronic atrial dilatation in the absence of overt CHF leads to increased vulnerability to AF through chronic regional inflammation and increased interstitial fibrosis 23 the existence of $\mathrm{AF}$ in $\mathrm{CAF}$ may not be affected by atrial stretch stimulation with exacerbated CHF.

In contrast, the clinical characteristic of PAF is represented as an 'alteration' compared to CAF. It was demon- strated that the later development of AF, but not antecedent $\mathrm{AF}$, was associated with increased mortality in CHF subjects! ${ }^{17}$ Another report showed that the later onset of AF during the CHF course is associated with clinical and hemodynamic deterioration, and may predispose patients to systemic thromboembolism and a poorer prognosis ${ }^{24} \mathrm{We}$ observed the reproducibility of PAF in conjunction with cardiac decompensation in most of the eventful PAF cases during the follow-up period. It should be reasonable to consider, therefore, that the later onset of AF, presented as PAF in the present study, can cause deteriorated hemodynamics leading to a poorer prognosis, while CAF can not.

\section{Clinical Implications and Future Prospects: Application to} New Management of $A F$ in $C H F$

The choice of long-term therapy of AF in CHF is the object of intense debate. Although it is unclear whether to control the rate vs rhythm despite the subgroups analysis of AFFIRM and RACE 3,25 which tended to support rhythm control, the results of studies specifically designed to examine populations of patients with $\mathrm{CHF}$, such as $\mathrm{AF}-\mathrm{CHF}^{26}$ are needed to draw more definite conclusions. The consensus up until now, reflected in current ACC/AHA/ESC guidelines on management of $\mathrm{AF}$, was that rhythm control should not be vigorously pursued in this clinical setting. 27

We did not demonstrate a beneficial outcome of the predominance of the rhythm control strategy in the present study, as indicated by the Intervention Group compared to rate control strategy in the Non-Intervention Group. It is 
true that the present study reached a limited conclusion for the treatment strategy for AF coincident with CHF because of its non-randomized, retrospective fashion. We could emphasize, however, that the prognosis of the PAF group was only comparable to that of the CAF group among the Non-intervention group in which no aggressive therapy for AF except ventricular rate control was undertaken. In other words, it is a reliable interpretation, even in this retrospective study, that the existence of PAF has prognostic significance. Therefore, we need to discuss which therapy should be recommended for $\mathrm{AF}$ in $\mathrm{CHF}$ patients, distinguishing PAF from CAF.

Except for the emergent cases with deteriorated circulatory hemodynamics due to the additive occurrence of $\mathrm{AF}$, conventional $\mathrm{CHF}$ management and rate control strategy without the defibrillation procedures should first of all be recommended in CHF patients with AF. When we encounter patients whose cardiac rhythms spontaneously convert from AF to SR with improving CHF status, we may propose specific management strategies. Therefore, the strategy for AF treatment can be optimized according to the pattern of AF onset and persistence because a phenotypic difference of AF could lead to a different clinical outcome in CHF. We might consider 2 ways of intervention for these PAF patients to improve the prognosis according to the presumable pathomechanisms stated above. The first possibility is the prevention of AF recurrence predominantly through the administration of preferable antiarrhythmic agents. For this purpose, amiodarone is an optimal candidate with significant potential to maintain SR, leading to lower mortality in CHF28 An AFFIRM study, however, demonstrated that only $35 \%$ of cases could maintain SR under the administration of amiodarone, while it was reported that PAF eventually developed into its chronic form in $77.2 \%$ of patients under conventional antiarrhythmic therapy during a 14-year-follow-up29 Komatsu et al reported that the longterm prognosis of patients with PAF varies with the response to antiarrhythmic drug therapy 30 The limitations of the rhythm control therapy may be recognized, considering the altered management policy of rate control, if AF has repeatedly occurred under the antiarrhythmic drug therapy. The other option is strict CHF control unless CHF status worsens, leading to the occurrence of AF. Optimal pharmacotherapy under established guidelines or a BNPguided management might approach this target 31,32 Further prospective studies are warranted to determine the optimal management strategy for $\mathrm{CHF}$ patients with $\mathrm{AF}$.

\section{Study Limitations}

Some limitations of the study must be acknowledged: (1) the study was carried out inside a single center in both a retrospective and nonrandomized fashion. The acquired data might be biased because the clinical judgment depended on the clinical status of each patient. (2) It would be ideal if there was no significant difference in the clinical backgrounds between SR and AF patients. This, however, must be impossible because AF itself may lead to pathological and hemodynamic changes. (3) Although patients were carefully followed up, asymptomatic AF cannot be ruled out completely, and conversely, spontaneous termination and reinitiation of persistent $\mathrm{AF}$ cannot be distinguished from CAF. Despite these limitations, the present study focused for the first time on the clinical significance of PAF coincident with cardiac decompensation in CHF management. This finding raises the possibility that prophylactic therapies reduce the repeated cardiac events of exacerbated $\mathrm{CHF}$ to these high-risk patients. Further studies addressing the pathogenesis, prevention, and the optimal management of the $\mathrm{AF}$ and $\mathrm{CHF}$ according to the phenotype of AF seem warranted.

\section{Acknowledgments}

This study was supported in part by research grants from the Postgraduate Research Project at Kitasato University, Kitasato University Research Grant for Young Researchers and the Parents' Association Grant of Kitasato University School of Medicine.

\section{References}

1. Go AS, Hylek EM, Phillips KA, Chang Y, Henault LE, Selby JV, et al. Prevalence of diagnosed atrial fibrillation in adults: National implications for rhythm management and stroke prevention: The Anticoagulation and Risk Factors in Atrial Fibrillation (ATRIA) Study. JAMA 2001; 285: 2370-2375.

2. Kannel WB, Abbott RD, Savage DD, McNamara PM. Coronary heart disease and atrial fibrillation: The Framingham Study. Am Heart J 1983; 106: 389-396.

3. The Atrial Fibrillation Follow-up Investigation of Rhythm Management (AFFIRM) Investigators. A comparison of rate control and rhythm control in patients with atrial fibrillation. N Engl J Med 2002; 347: $1825-1833$.

4. Haldeman GA, Croft JB, Giles WH, Rashidee A. Hospitalization of patients with heart failure: National Hospital Discharge Survey, 1985 to 1995 . Am Heart J 1999; 137: 352-360.

5. Benjamin EJ, Levy D, Vaziri SM, D’Agostino RB, Belanger AJ, Wolf PA. Independent risk factors for atrial fibrillation in a population-based cohort: The Framingham Heart Study. JAMA 1994; 271: $840-844$.

6. Baldasseroni S, De Biase L, Fresco C, Marchionni N, Marini M, Masotti G, et al. Cumulative effect of complete left bundle-branch block and chronic atrial fibrillation on 1-year mortality and hospitalization in patients with congestive heart failure: A report from the Italian network on congestive heart failure (in-CHF database). Eur Heart J 2002; 23: 1692-1698.

7. Dries DL, Exner DV, Gersh BJ, Domanski MJ, Waclawiw MA, Stevenson LW. Atrial fibrillation is associated with an increased risk for mortality and heart failure progression in patients with asymptomatic and symptomatic left ventricular systolic dysfunction: A retrospective analysis of the SOLVD trials: Studies of Left Ventricular Dysfunction. J Am Coll Cardiol 1998; 32: 695-703.

8. Crijns HJ, Tjeerdsma G, de Kam PJ, Boomsma F, van Gelder IC, van den Berg MP, et al. Prognostic value of the presence and development of atrial fibrillation in patients with advanced chronic heart failure. Eur Heart J 2000; 21: 1238-1245.

9. Carson PE, Johnson GR, Dunkman WB, Fletcher RD, Farrell L, Cohn JN. The influence of atrial fibrillation on prognosis in mild to moderate heart failure: The V-HeFT Studies: The V-HeFT VA Cooperative Studies Group. Circulation 1993; 87(Suppl VI): VI-102VI-110.

10. Takarada A, Kurogane H, Hayashi T, Fujimoto T, Yasaka Y, Fukumoto Y, et al. Prognostic significance of atrial fibrillation in dilated cardiomyopathy. Jpn Heart J 1993; 34: 749-758.

11. Naito M, David D, Michelson EL, Schaffenburg M, Dreifus LS. The hemodynamic consequences of cardiac arrhythmias: Evaluation of the relative roles of abnormal atrioventricular sequencing, irregularity of ventricular rhythm and atrial fibrillation in a canine model. Am Heart J 1983; 106: 284-291.

12. Shinbane JS, Wood MA, Jensen DN, Ellenbogen KA, Fitzpatrick AP, Scheinman MM. Tachycardia-induced cardiomyopathy: A review of animal models and clinical studies. J Am Coll Cardiol 1997; 29: $709-715$

13. Francis GS, Benedict C, Johnstone DE, Kirlin PC, Nicklas J, Liang $\mathrm{CS}$, et al. Comparison of neuroendocrine activation in patients with left ventricular dysfunction with and without congestive heart failure: A substudy of the Studies of Left Ventricular Dysfunction (SOLVD). Circulation 1990; 82: 1724-1729.

14. Allessie MA, Boyden PA, Camm AJ, Kleber AG, Lab MJ, Legato MJ, et al. Pathophysiology and prevention of atrial fibrillation. Circulation 2001; 103: 769-777.

15. Middlekauff HR, Stevenson WG, Stevenson LW. Prognostic significance of atrial fibrillation in advanced heart failure: A study of 390 patients. Circulation 1991; 84: 40-48.

16. Mahoney P, Kimmel S, DeNofrio D, Wahl P, Loh E. Prognostic 
significance of atrial fibrillation in patients at a tertiary medical center referred for heart transplantation because of severe heart failure. Am J Cardiol 1999; 83: 1544-1547.

17. Wang TJ, Larson MG, Levy D, Vasan RS, Leip EP, Wolf PA, et al. Temporal relations of atrial fibrillation and congestive heart failure and their joint influence on mortality: The Framingham Heart Study. Circulation 2003; 107: 2920-2925.

18. Scardi S, Mazzone C, Pandullo C, Goldstein D, Poletti A, Humar F. Lone atrial fibrillation: Prognostic differences between paroxysmal and chronic forms after 10 years of follow-up. Am Heart J 1999; 137: $686-691$

19. Li D, Fareh S, Leung TK, Nattel S. Promotion of atrial fibrillation by heart failure in dogs: Atrial remodeling of a different sort. Circulation 1999; 100: 87-95.

20. Yu WC, Chen SA, Chiang CE, Tai CT, Lee SH, Chiou CW, et al. Effect of high intensity drive train stimulation on dispersion of atrial refractoriness: Role of autonomic nervous system. J Am Coll Cardiol 1997; 29: 1000-1006.

21. Tsang TS, Gersh BJ, Appleton CP, Tajik AJ, Barnes ME, Bailey KR, et al. Left ventricular diastolic dysfunction as a predictor of the first diagnosed nonvalvular atrial fibrillation in 840 elderly men and women. J Am Coll Cardiol 2002; 40: 1636-1644.

22. Schwammenthal E, Adler Y, Amichai K, Sagie A, Behar S, Hod H, et al. Prognostic value of global myocardial performance indices in acute myocardial infarction: Comparison to measures of systolic and diastolic left ventricular function. Chest 2003; 124: 1645-1651.

23. Verheule S, Wilson E, Everett T 4th, Shanbhag S, Golden C, Olgin J. Alterations in atrial electrophysiology and tissue structure in a canine model of chronic atrial dilatation due to mitral regurgitation. $\mathrm{Circu}$ lation 2003; 107: 2615-2622.

24. Pozzoli M, Cioffi G, Traversi E, Pinna GD, Cobelli F, Tavazzi L. Predictors of primary atrial fibrillation and concomitant clinical and hemodynamic changes in patients with chronic heart failure: A prospective study in 344 patients with baseline sinus rhythm. J Am Coll Cardiol 1998; 32: 197-204.

25. Van Gelder IC, Hagens VE, Bosker HA, Kingma JH, Kamp O, Kingma T, et al. A comparison of rate control and rhythm control in patients with recurrent persistent atrial fibrillation. $N$ Engl J Med
2002; 347: $1834-1840$.

26. The AF-CHF Trial Investigators. Rationale and design of a study assessing treatment strategies of atrial fibrillation in patients with heart failure: The Atrial Fibrillation and Congestive Heart Failure (AF-CHF) trial. Am Heart J 2002; 144: 597-607.

27. Fuster V, Ryden LE, Asinger RW, Cannom DS, Crijns HJ, Frye RL, et al. ACC/AHA/ESC guidelines for the management of patients with atrial fibrillation: A report of the American College of Cardiology/American Heart Association Task Force on Practice Guidelines and the European Society of Cardiology Committee for Practice Guidelines and Policy Conferences (Committee to develop guidelines for the management of patients with atrial fibrillation) developed in collaboration with the North American Society of Pacing and Electrophysiology. Eur Heart J 2001; 22: 1852-1923.

28. Deedwania PC, Singh BN, Ellenbogen K, Fisher S, Fletcher R, Singh $\mathrm{SN}$. Spontaneous conversion and maintenance of sinus rhythm by amiodarone in patients with heart failure and atrial fibrillation: $\mathrm{Ob}$ servations from the veterans affairs congestive heart failure survival trial of antiarrhythmic therapy (CHF-STAT): The Department of Veterans Affairs CHF-STAT Investigators. Circulation 1998; 98: $2574-2579$.

29. Kato T, Yamashita T, Sagara K, Iinuma H, Fu LT. Progressive nature of paroxysmal atrial fibrillation: Observations from a 14-year follow-up study. Circ J 2004; 68: 568-572.

30. Komatsu T, Nakamura S, Suzuki O, Horiuchi D, Yomogida K, Okumura K. Long-term prognosis of patients with paroxysmal atrial fibrillation depends on their response to antiarrhythmic therapy. Circ J 2004; 68: 729-733.

31. Hunt SA, Baker DW, Chin MH, Cinquegrani MP, Feldman AM, Francis GS, et al. ACC/AHA Guidelines for the Evaluation and Management of Chronic Heart Failure in the Adult: Executive Summary A Report of the American College of Cardiology/American Heart Association Task Force on Practice Guidelines. Circulation 2001; 104: 2996-3007.

32. Inomata T, Nishii M, Takehana H, Koitabashi T, Takeuchi I, Nakano $\mathrm{H}$, et al. Brain natriuretic peptide-guided treatment reduces cardiovascular events of heart failure in outpatient management (abstract). Circulation 2003; 108(Suppl): V-446. 